\title{
Tingles, Tetany, and Electrolyte Derangements
}

\author{
Amardeep Singh ${ }^{1}$, Ramandeep Kaur ${ }^{2}$, Bhagwan Dass ${ }^{1}$, Abutaleb Ejaz ${ }^{1}$ \\ 1. Nephrology, University of Florida Health, Gainesville, USA 2. Miscellaneous, Virginia Commonwealth University, \\ Richmond, USA
}

Corresponding author: Amardeep Singh, amarskdeep@gmail.com

\begin{abstract}
We report a patient who presented with anxiety, hyperventilation, perioral paresthesia, and tingling in the fingers associated with hypomagnesemia, hypocalcemia, and hypokalemia. We discuss the possible mechanistic basis for sequence of events that may have led to this presentation.
\end{abstract}

Categories: Family/General Practice, Internal Medicine, Nephrology

Keywords: hypomagnesemia, hypocalcemia, hypokalemia, mechanisms, electrolyte disturbances, tetany, paresthesia, chronic kidney disease, genetic syndromes, general internal medicine

\section{Introduction}

Hypomagnesemia is defined as serum magnesium level $<1.5 \mathrm{mEq} / \mathrm{L}$ and can be seen in $\sim 12 \%$ of hospitalized patients. It is typically associated with volume expansion, chronic diarrhea, diuretic and antibiotic use, and malnutrition [1]. Hypomagnesemia can cause life-threatening cardiac arrhythmias through its influence on potassium and calcium homeostasis. We discuss the interconnectedness of magnesium, potassium, and calcium in this case report.

\section{Case Presentation}

A 47-year-old female presented to the ER with severe anxiety, palpitations, and hyperventilation associated with perioral tingling and numbness of the fingers that started several hours previously. She had similar episodes two years ago without elucidations of the etiology of her symptoms. She was not on any medication; social history was negative for alcohol or illicit drug use.

Received 03/24/2020

Review began 04/05/2020 Review ended 04/20/2020 Published 04/27/2020

\section{() Copyright 2020}

Singh et al. This is an open access article distributed under the terms of the Creative Commons Attribution License CC-BY 4.0., which permits unrestricted use, distribution, and reproduction in any medium, provided the original author and source are credited.
On physical examination, blood pressure was $131 / 83 \mathrm{mmHg}$, heart rate 122 beats per minute, respiratory rate 16 per minute, temperature $36.7^{\circ} \mathrm{C}$, and oxygen saturation $98 \%$. The patient was alert, oriented, and appeared much younger than the stated age. Chvostek and Trousseau signs were negative. She, however, continued to complain of perioral paresthesia and twitching (which was not visually evident).

Cardiovascular, respiratory, gastrointestinal, and neurological examinations were unremarkable. Laboratory findings included, serum sodium $140 \mathrm{mEq} / \mathrm{L}$ (normal 135-145 mEq/L), potassium $2.7 \mathrm{mEq} / \mathrm{L}$ (normal 3.5-5.0 $\mathrm{mEq} / \mathrm{L}$ ), chloride $105 \mathrm{mEq} / \mathrm{L}$ (normal 98-106 mEq/L), bicarbonate $13 \mathrm{mEq} / \mathrm{L}$ (normal 23-28 mEq/L), blood urea nitrogen (BUN) $29 \mathrm{mg} / \mathrm{dL}$ (normal 7-20 mg/dL), creatinine $2.5 \mathrm{mg} / \mathrm{dL}$ (normal 0.7-1.3 mg/dL), calcium 7.8 $\mathrm{mg} / \mathrm{dL}$ (normal 9-10.5 mg/dL), magnesium $0.9 \mathrm{mg} / \mathrm{dL}$ (normal 1.5-2.4 mg/dL), phosphorus $2.3 \mathrm{mg} / \mathrm{dL}$ (normal 3-4.5 mg/dL), ionized calcium $1.01 \mathrm{mmol} / \mathrm{L}$ (normal 1.2-1.4 mmol/L), parathyroid hormone (PTH) $998 \mathrm{pg} / \mathrm{mL}$ (normal 10-65 pg/mL), anion gap 12 and delta gap -1 (compatible with high anion gap acidosis). Urine $\mathrm{pH}$ was 7.4, random urine calcium and creatinine were 3 and $29.9 \mathrm{mg} / \mathrm{dL}$, respectively. Calculated fractional excretion of calcium was $0.03 \%$. Urine drug screen for amphetamines, methamphetamines, benzodiazepines, barbiturates, marijuana, cocaine, phencyclidine (PCP), methadone, and opioids were negative. A 24-h urine calcium was $47 \mathrm{mg} / 24 \mathrm{~h}$ (normal 50-100 mg/24 h). Plasma renin activity $1.4 \mathrm{ng} / \mathrm{mL} / \mathrm{h}$ (normal 2.9-24 $\mathrm{ng} / \mathrm{mL} / \mathrm{h}$ ), supine aldosterone $2.3 \mathrm{ng} / \mathrm{dL}$ (normal 3-35 ng/dL), 25-OH vitamin D $28 \mathrm{ng} / \mathrm{mL}$ (normal 20-50 $\mathrm{ng} / \mathrm{mL}$ ), and 1,25-OH vitamin D $51 \mathrm{ng} / \mathrm{mL}$ (normal 25-65 ng/mL). Arterial blood gas was not available.

Electrocardiogram revealed sinus tachycardia with a PR interval of $13 \mathrm{~ms}$, QRS of $87 \mathrm{~ms}$, and QT $282 \mathrm{~ms}$. Fluid resuscitation was initiated with $2 \mathrm{~L}$ of normal saline. Additives included magnesium sulfate, followed by potassium chloride and calcium chloride. Serum potassium improved to $3.4 \mathrm{mEq} / \mathrm{L}$, magnesium to 2.2 $\mathrm{mEq} / \mathrm{L}$, and calcium to $1.25 \mathrm{mmol} / \mathrm{L}$ and the patient had an output of $1.2 \mathrm{~L}$. In the next four days her electrolytes returned to normal levels, BUN and serum creatinine improved to 10 and $1.1 \mathrm{mg} / \mathrm{dL}$, respectively. She was discharged from the hospital with instruction for outpatient follow-up within seven days. She did not show-up for her clinic appointment and was lost to follow-up.

\section{Discussion}

The patient's symptoms improved with correction of hypomagnesemia and hypocalcemia. The pivotal question is the etiology and the mechanisms involved here. A brief discussion of calcium, magnesium, and potassium homeostasis is in order. The daily dietary calcium load $(\sim 1000 \mathrm{mg})$ is predominantly excreted in feces (90\%) and only $10 \%$ by the kidneys. PTH and 1,25-dihydroxyvitamin D are the principal players in 
normal calcium homeostasis. A decrease in the serum ionized calcium concentration and a decrease in serum levels of 1,25(OH)2-D trigger PTH secretion leading to increased conversion of 25-hydroxy $(\mathrm{OH})$ vitamin $\mathrm{D}$ to the potent 1,25-dihydroxyvitamin D by the kidneys and stimulation of increased intestinal absorption of calcium [2].

In the kidney, approximately $70 \%$ of filtered calcium is reabsorbed in the proximal tubule through a paracellular pathway predominantly through solvent drag [3]. Some $20 \%$ of the filtered calcium is reabsorbed by the thick ascending limb by paracellular pathway (tight junctions composed mostly of paracellin-1) driven by lumen-positive voltage created and maintained by NKCC2, $\mathrm{Na}+\mathrm{K}+-\mathrm{ATPase}$, and chloride channel ClC$\mathrm{Kb}$ [4]. Renal outer medullary potassium channel (ROMK) mediates $\mathrm{K}+$ ion recycling across apical plasma membranes to the luminal fluid of the thick ascending limb and is responsible for generating the lumenpositive voltage that serves as a driving force for the cation-selective paracellular movement of $\mathrm{Ca} 2+, \mathrm{Mg} 2+$, and of additional $\mathrm{Na}+$ absorption by the TAL. ROMK is regulated by calcium sensing receptors [5].

Extracellular Ca2+ inhibits both NKCC2 and ROMK, decreasing salt reabsorption. Only $8 \%$ of filtered calcium is reabsorbed by the distal tubule via active transcellular pathways.

Filtered magnesium is reabsorbed in the proximal tubule ( $25 \%)$ and thick ascending limb ( $60 \%)$ via paracellular pathways involving transmembrane proteins paracellin-1 and claudin-19 and driven by potential gradients. Magnesium is also reabsorbed in the distal tubules ( $\sim 5)$ via transcellular pathways that involve transient receptor potential (TRPM6) [6]. Magnesium deficiency is known to exacerbate urinary potassium loss by increasing distal potassium secretion. A decrease in intracellular magnesium releases the magnesium-mediated inhibition of ROMK channels and increases potassium secretion. This process requires concomitant increase in distal sodium delivery or elevated aldosterone levels.

In our patient serum potassium, magnesium, and calcium improved with supplements. Low fractional excretion of calcium was an appropriate response by the kidneys to conserve calcium in the presence of hypocalcemia, possibly via increased distal tubule active transcellular pathways. The sequence of events that resulted in the patient's symptoms is uncertain, but may have been precipitated by hypomagnesemia, followed by hypokalemia and hypocalcemia manifesting as perioral tingling and numbness of the fingers via mechanisms discussed above. Hypocalcemia was the presumed trigger for increased PTH secretion. The etiology of hypomagnesemia, whether acquired (poor dietary intake, gastrointestinal absorption issues, or self-induced) versus genetic factors remains unknown.

\section{Conclusions}

Hypomagnesemia can cause adverse clinical events through its effect on downstream systems that control potassium and calcium as shown in this case. The serum magnesium level that can result in adverse events is unknown as there is no linear correlation with total body magnesium and serum magnesium levels. Correction of magnesium significantly improved potassium and magnesium levels and symptoms in this patient. Our case offers a glimpse of the complex interconnectedness of ion transport systems in the human body.

\section{Additional Information \\ Disclosures}

Human subjects: Consent was obtained by all participants in this study. Conflicts of interest: In compliance with the ICMJE uniform disclosure form, all authors declare the following: Payment/services info: All authors have declared that no financial support was received from any organization for the submitted work. Financial relationships: All authors have declared that they have no financial relationships at present or within the previous three years with any organizations that might have an interest in the submitted work. Other relationships: All authors have declared that there are no other relationships or activities that could appear to have influenced the submitted work.

\section{References}

1. Lo Piano F, Corsonello A, Corica F: Magnesium and elderly patient: the explored paths and the ones to be explored: a review. Magnes Res. 2019, 32:1-15.

2. Goltzman D, Mannstadt M, Marcocci C: Physiology of the calcium-parathyroid hormone-vitamin D axis . Front Horm Res. 2018, 50:1-13.

3. Frick KK, Bushinsky DA: Molecular mechanisms of primary hypercalciuria . J Am Soc Nephrol. 2003, 14:1082-1095. 10.1097/01.asn.0000062960.26868.17

4. Blanchard A, Jeunemaitre X, Coudol P, et al.: Paracellin-1 is critical for magnesium and calcium reabsorption in the human thick ascending limb of Henle. Kidney Int. 2001, 59:2206-2215. 10.1046/j.15231755.2001.00736.x

5. Cha SK, Huang C, Ding Y, Qi X, Huang CL, Miller RT: Calcium-sensing receptor decreases cell surface expression of the inwardly rectifying K+ channel Kir4.1. J Biol Chem. 2011, 286:1828-1835. 10.1074/jbc.M110.160390

6. Huang CL, Kuo E: Mechanism of hypokalemia in magnesium deficiency . J Am Soc Nephrol. 2007, 18:26492652. 10.1681/ASN.2007070792 